\title{
МИКРОСТРУКТУРНЫЕ ОСОБЕННОСТИ И НАПРЯЖЕННОЕ СОСТОЯНИЕ СОЛЯНЫХ ПОРОД
}

\author{
В.Н. Токсаров \\ Горный институт УрО РАН, г. Пермь
}

\begin{abstract}
Аннотация: Проведен анализ изучения природных солей, основанного на взаимосвязи микроструктурных особенностей каменной соли с уровнем дифференциальных напряжений, на различных месторождениях. Установлено систематическое уменьшение размера субзерна в каменной соли с увеличением напряжения вне зависимости от температуры и деформации (при величине деформации выше критического значения, равного примерно 1\%). Зная величину среднего размера субзерна, можно судить о величине палеонапряжений, а также эволюции соляных структур. Обзор микроструктурных исследований природных солей показал, что диапазон величины дифференциальных напряжений в массиве составляет $0,5 \div 5,5$ МПа.

Ключевые слова: каменная соль, размер субзерна, плотность свободных дислокаций, рекристаллизованное зерно, дифференциальные напряжения, пластовая соль, соляной купол, антиклиналь, палеонапряжения.
\end{abstract}

\section{Введение}

Информация о величине напряжений, как настоящих, так и прошлых, в природных каменных солях может быть использована при изучении механизма эволюции основных геологических структур. Знание текущего напряженного состояния в слоистых, купольных и антиклинальных каменных солях, рассматриваемых с целью размещения в них отходов ядерного производства, необходимо для прогнозирования термомеханической реакции во время выемки, погрузки и извлечения. Величина палеонапряжений может быть получена по результатам исследования микромеханических особенностей природной каменной соли.

Ообычно исследователи включают в перечень микроструктурных особенностей солей, изучаемых в режиме установившейся ползучести, связанных с разностью главных напряжений и не зависящих от температуры, деформации и скорости деформации (за пределами критических значений), следующие параметры: размер рекристаллизованного зерна, размер субзерен и плотность свободных дислокаций. Из них размер рекристаллизованного зерна является наиболее надежным индикатором величины девиаторного напряжения, а плотность свободных дислокаций, вероятно, наименее надежным [12]. При этом наиболее перспективным с учетом трудоемкости и точности проведения экспериментов по оценке величины дифференциальных напряжений является использование среднего размера субзерна.

\section{Взаимосвязь размера субзерна каменной соли от величины девиаторного напряжения}

Расчеты дифференциальных напряжений и скоростей деформаций в большинстве материалов, деформирующихся в результате процессов дислокационной ползучести, показывают, что размер установившегося субзерна обратно пропорционален разности напряжений $\left(\sigma_{1}-\sigma_{3}\right)$ и не зависит от других переменных

$$
D=k \sigma^{-m}
$$

где $D$ - средний размер субзерна, $\mu m ; \sigma$ - величина дифференциального напряжения, МПа; $k$ и $m$ - материальные константы [8]. 
По другим данным при расчете средних размеров субзерен, полученных в процессе динамического восстановления, в формулу добавляется модуль упругости

$$
D=k(\sigma / E)^{-m}
$$

где $E$ - модуль упругости, ГПа [12].

Исследованиями установлено, что размер субзерен монотонно уменьшается с увеличением разницы напряжений, независимо от температуры и деформации (> 1\%).

Для определения среднего размера субзерен шлифы галита анализируются с использованием микроскопии в проходящем и отраженном свете. Перед экспериментом соляные пластины протравливаются в течение 30-50 секунд в различных растворах (5молярный раствор $\mathrm{NaCl}$, ледяная уксусная кислота и т.д.).

\section{Анализ результатов оценки дифференциальных природных напряжений в массиве на различных месторождениях по результатам изучения микроструктуры каменной соли}

В табл. 1 приведены результаты оценки дифференциальных природных напряжений в массиве на различных месторождениях по результатам изучения среднего размера субзерна в каменной соли [1-12].

Сводка оценок палеонапряжений для различных месторождений, полученные

Таблица 1 по результатам изучения микроструктурам соляных пород

\begin{tabular}{|c|c|c|c|}
\hline $\begin{array}{c}\text { № } \\
\text { II/II }\end{array}$ & Месторождение & $\begin{array}{c}\text { Дифферен. } \\
\text { напряжение, МПа }\end{array}$ & $\begin{array}{c}\text { Геологическая } \\
\text { характеристика }\end{array}$ \\
\hline 1 & Горлебен (Германия) & $1,10 \div 1,30$ & Соляной купол \\
\hline 2 & Qum Kuh (Иран) & $3,10 \div 4,80$ & Соляной диапир \\
\hline 3 & Морслебен (Германия) & $1,20 \div 2,90$ & Соляной купол \\
\hline 4 & $\begin{array}{c}\text { Хасельгебирге } \\
\text { (Австрия) }\end{array}$ & $2,00 \div 5,40$ & $\begin{array}{c}\text { Смесь соли с грязевы- } \\
\text { ми породами и текто- } \\
\text { нитом } \\
\end{array}$ \\
\hline 5 & Горлебен (Германия) & $2,28 \div 2,97$ & Соляной купол \\
\hline 6 & Хенгело (Нидерланды) & $0,45 \div 0,97$ & Пластовая соль \\
\hline 7 & Клодава (Польша) & $0,90 \div 3,10$ & Соляной купол \\
\hline 8 & Гармсар Хиллз (Иран) & $1,40 \div 2,00$ & Соляная экструзия \\
\hline 9 & Birba, Haweel (Оман) & $1,61 \div 1,94$ & Соляной диапир \\
\hline 10 & Нойхоф (Германия) & $3,8 \div 4,8$ & Складчатая соль \\
\hline 11 & Лион (ш. Канзас, США) & 0,52 & Пластовая соль \\
\hline 12 & Саладо (ш. Нью-Мексико, США) & 0,56 & Пластовая соль \\
\hline 13 & Лансинг (ш. Нью-Йорк, США) & 0,68 & Пластовая соль \\
\hline 14 & Лансинг (конц. напряжений) & 2,45 & Пластовая соль \\
\hline 15 & Кливленд (ш. Огайо, США) & 1,02 & Пластовая соль \\
\hline 16 & Гранд-Салин (ш. Техас, США) & 0,58 & Соляной купол \\
\hline 17 & $\begin{array}{c}\text { Остров Эйвери (ш. Луизиана, } \\
\text { США) }\end{array}$ & 1,10 & Соляной купол \\
\hline 18 & Asse (Германия) & 0,85 & Антиклиналь \\
\hline
\end{tabular}


Анализ полученных данных показал, что величина дифференциальных природных напряжений в соляных массивах варьируется примерно в диапазоне от 0,5 до 5,5 МПа. Самые низкие оценки напряжений получены в пластовых солях в Нидерландах, тогда как более высокие оценки получены из мест, где соль сильно деформирована (например, в соляных куполах). В более чистой соли величина напряжений меньше (например, в соляном куполе на острове Эйвери), чем в солях с различными примесями (например, в Хасельбирге). В работе [5] также отмечается, что более высокие значения ( 3 МПа) в пределах Горлебена получены на участке повышенных деформаций соляных пород, расположенных в непосредственной близости от более плотного слоя ангидрита.

В [12] приведены данные о величине природных напряжений для семи соляных структур (пласт, купол, антиклиналь). На основе полученных данных о величине субзерен для купольной соли расчетное максимальное девиаторное напряжение равно 1,1 МПа и менее. Отмечается, что более высокие девиаторные напряжения могут возникать на участках соляного купола, содержащих нечистую соль, о чем свидетельствует один набор данных из восьми. Так, соляной массив в Лансинге (штат Мичиган, США) испытал наибольшее девиаторное напряжение, равное 2,34 МПа (табл. 1). Анализы субзерен показали концентрации напряжений вокруг зерен ангидрита, что, повидимому, является вероятной причиной относительно высокого девиаторного напряжения по сравнению с другими семью наборами данных (рис. 3).

\section{Заключение}

1. Весьма перспективным методом оценки палеонапряжений в соляных массивах являются микроструктурные исследования природной каменной соли. Метод основан на взаимосвязи размера субзерен с величиной напряжений: вне зависимости от температуры и деформации (при величине деформации выше критического значения, равного примерно 1\%) с увеличением дифференциальных напряжений в породе отмечается уменьшение размера субзерна.

2. Проведен анализ изучения природных солей на различных месторождениях, основанного на взаимосвязи микроструктурных особенностей каменной соли с уровнем дифференциальных напряжений. Обзор микроструктурных исследований природных солей показал, что диапазон величины дифференциальных напряжений в массиве составляет 0,5 $\div 5,5$ МПа. Предварительно установлено, что величина девиаторных напряжений в соляном массиве может зависеть от степени деформированности соли и наличия в ней примеси.

\section{Исследование выполнено при финансовой поддержке РФФИ в рамках научного проекта №20-45-596011 и программы ФНИ (проект № 0422-2019-0148-C-01).}

\section{БИБЛИОГРАФИЧЕСКИЙ СПИСОК}

1. Thiemeyer N., Zulauf G., Mertineit M., Linckens J., Pusch M., Hammer J. Microfabrics and 3D grain shape of Gorleben rock salt: constraints on deformation mechanisms and paleodifferential stress // Tectonophysics. -2016. -V. 676. - P. 1-19. - DOI: 10.1016/j.tecto.2016.02.046.

2. Desbois G., Urai J.L., de Bresser J. Fluid distribution in grain boundaries of natural fine-grained rock salt deformed at low differential stress (Qom Kuh salt fountain, central Iran): Implications for rheology and transport properties // Journal of structural geology. - 2012. - V. 43. - P. 128-143. - DOI: 10.1016/j.jsg.2012.07.002.

3. Desbois G., Závada P., Schléder Z. Urai J.L. Deformation and Recrystallization Mechanisms in Actively Extruding Salt Fountain: Microstructural Evidence for a Switch in Deformation Mechanisms with Increased Availability of Meteoric Water and Decreased Grain Size (Qum Kuh, Central Iran) // Journal of Structural Geology. - 2010. - V. 32, № 4. - P. 580-594. - DOI: 10.1016/j.jsg.2010.03.005. 
4. Kneuker T., Zulauf G., Mertineit M., Behlau J., Hammer J. The impact of finite strain on deformation mechanisms of permian stassfurt rock salt at the Morsleben site (Germany): Constraints from microfabric studies and EBSD analyses // Zeitschrift der Deutschen Gesellschaft für geowissenschaften. - 2014. - V. 165 № 1. - P. 91-106. - DOI: 10.1127/1860-1804/2013/0041.

5. Leitner C., Neubauer F., Urai J.L. Schoenherr J. Structure and evolution of a rocksalt-mudrock-tectonite: The haselgebirge in the Northern Calcareous Alps // Journal of Structural Geology. - 2011. - V. 33, № 5. P. 970-984. - DOI: 10.1016/j.jsg.2011.02.008.

6. Mertineit M., Schramm M., Hammer J.б Zulauf G. Deformation of anhydrite rocks (Gorleben-Bank, Z3OSM) in a high-strain domain of the Gorleben salt dome, Germany // Zeitschrift der Deutschen Gesellschaft für geowissenschaften. - 2014. - V. 165 № 1. - P. 49-62. - DOI: 10.1127/1860-1804/2014/0048.

7. Schleder Z., Urai J.L. Microstructural evolution of deformation-modified primary halite from the Middle triassic Rot formation at Hengelo, the Netherlands // International journal of Earth Sciences. -2005. - V. 94, № 5-6. - P. 941-955. - DOI: 10.1007/s00531-005-0503-2.

8. Schléder Z., Burliga S., Urai J.L. Dynamic and static recrystallization-related microstructures in halite samples from the Klodawa salt wall (Central Poland) as revealed by gamma-irradiation // Neues jahrbuch fur mineralogie-abhandlungen. - 2007. - V. 184, № 1. - P. 17-28. - DOI: 10.1127/0077-7757/2007/0079.

9. Schléder Z., Urai J.L. Deformation and recrystallization mechanisms in mylonitic shear zones in naturally deformed extrusive eocene-oligocene rocksalt from eyvanekey plateau and Garmsar Hills (Central Iran) // Journal of Structural Geology. - 2007. - V. 29, № 2. - P. 241-255. - DOI: 10.1016/j.jsg.2006.08.014.

10. Schoenherr J., Urai L.L, Kukla P.A., Littke R., Schléder Z., Larroque J.M. , Newall M.J., Al-Abry N., AlSiyabi H.A., Rawahi Z. Limits to the sealing capacity of rock salt: A case Study of the infra-cambrian ara salt from the South Oman salt basin // AAPG Bulletin. - 2007. - V. 91, № 11. - P. 1541-1557. - DOI: $10.1306 / 06200706122$.

11. Závada P., Desbois G., Schwedt A., Lexa O., Urai J.L. Extreme ductile deformation of fine-grained salt by coupled solution precipitation creep and microcracking: microstructural evidence from perennial zechstein sequence (Neuhof salt mine, Germany) // Journal of Structural Geology. - 2012. - V. 37. - P. 89-104. DOI: $10.1016 /$ j.jsg.2012.01.024.

12. Carter N.L., Hansen F.D., Senseny P.E. Stress magnitudes in natural rock salt // Journal of geo-physical research. - 1982. - V. 87, № B11.P. 9289-9300. - DOI: 10.1029/JB087iB11p09289.

УДК 622.831

DOI:10.7242/echo.2021.2.7

\title{
О ВОЗМОЖНОСТИ МИНИМИЗАЦИИ РИСКА НАРУШЕНИЯ СПЛОШНОСТИ ВОДОЗАЩИТНОЙ ТОЛЩИ НА ПОТЕНЦИАЛЬНО ОПАСНЫХ УЧАСТКАХ
}

\author{
А.К. Федосеев \\ Горный институт УрО РАН, г. Пермь
}

\begin{abstract}
Аннотация: При значительных деформациях породного массива вокруг отработанного пространства традиционные методы защиты рудника от затопления, такие как закладка очистных камер, часто не могут обеспечить сохранность водозащитной толщи. В случае, если местом локализации возможного нарушения является охранный целик вокруг разведочной скважины, одним из возможных методов предотвращения проникновения пресных вод в выработанное пространство является подработка охранного целика.

На примере критической ситуации в юго-западной части рудника БКРУ-4 (Березники, Россия) рассмотрены основные методологические аспекты геомеханической оценки влияния подработки охранного целика на сохранность водозащитной толщи для различных вариантов создания зоны смягчения. Деформирование слоистого соляного массива, подработанного камерной системой разработки, описывалось моделью идеальной упруго-пластичной среды с внутренним трением. В качестве критерия пластичности в области сжатия использовалась параболическая огибающая кругов Мора.

Ключевые слова: калийные рудники, напряженно-деформированное состояние, математическое моделирование, метод конечных элементов.
\end{abstract}

В условиях значительных деформаций пород вокруг горных выработок охранные целики, оставление которых призвано обеспечить сохранность разведочных скважин, 